\title{
RANITIDINE CONTROLLED RELEASE ANTI-REFLUX SUSPENSION FOR GASTRO- OESOPHAGEAL REFLUX DISEASE AND IT'S IN VITRO EVALUATION
}

\author{
SANGMESH R. TORNEa,b, SHEELA A. ${ }^{\text {b* }}$, SARADA N. C. b
}

andia Innovation Center, DuPont Nutrition and Health (Formerly FMC Health and Nutrition), Bangalore, India, bDepartment of Chemistry, School of Advanced Sciences, Vellore Institute of Technology, Vellore, Tamil Nadu, India

Email: asheela@vit.ac.in

Received: 28 Jul 2018, Revised and Accepted: 19 Nov 2018

\section{ABSTRACT}

Objective: The aim of this work was to develop triple action controlled release anti-reflux suspension of ranitidine and its in-vitro evaluation of anti-reflux and controlled release properties.

Methods: The formulation was optimized using sodium alginate as a gelling agent along with calcium carbonate, sodium bicarbonate, magnesium hydroxide, aluminium hydroxide as alkalizing agents and colloidal microcrystalline cellulose (MCC) as a suspending agent at various concentrations and arrived at an optimized formulation for its best quality attributes. To avoid initial release in water before administration, ranitidine coated MCC sphere was incorporated into powder formulation and subjected to in vitro characteristics like raft strength, acid neutralizing capacity, $\mathrm{pH}$, viscosity and dissolution study. The obtained results were assessed using Minitab 17 statistical software to conclude the study design.

Results: Formulation containing $300 \mathrm{mg}$ of ranitidine along with $750 \mathrm{mg}$ alginate has shown better anti-reflux characteristics like raft strength $18 \pm 2 \mathrm{~g}$, acid neutralizing capacity $17 \pm 1 \mathrm{mEq}$ compared to other formulations. This formulation has also shows zero-order controlled release in the simulated gastric fluid (SGF) up to $10 \mathrm{~h}$ compared to the formulation without alginate. Further, to this optimized formulation has shown negligible change in the assay of ranitidine even after $3 \mathrm{mo}$ at $40^{\circ} \mathrm{C}$ temperature and $75 \% \mathrm{RH}$.

Conclusion: The developed stable sustained release powder for suspension has the combined therapeutic efficacy as an antacid and anti-reflux drug suitable for the management and treatment of gastro-oesophageal reflux disease (GERD) unlike the existing drugs possessing only reflux resistance action.

Keywords: Suspension, Alginate, Gastro-oesophageal reflux disease, Raft, Controlled release, Ranitidine

(c) 2019 The Authors. Published by Innovare Academic Sciences Pvt Ltd. This is an open-access article under the CC BY license (http://creativecommons.org/licenses/by/4.0/) DOI: http://dx.doi.org/10.22159/ijap.2019v11i1.28754

\section{INTRODUCTION}

Anti-reflux formulation has been known since the last couple of decades. Alginate suspension plays a vital role in acting against refluxes in the management and treatment of gastro-oesophageal reflux disease (GERD) [1-3]. Alginate liquid suspension mainly acts against symptoms associated with GERD. Anti-reflux formulations are available in different dosage forms in the global market as a liquid suspension $[3,4]$ as granules [5] for suspension and as a chewable tablet [6]. A very few attempts have only been made towards the development of anti-reflux formulation and thus has a wide scope for further exploration.

GERD is diagnosed with symptoms of acid reflux, in which stomach acid and content backs up into the esophagus resulting in heartburn, regurgitation. Long-term GERD can also bring about reflux esophagitis or Barrett's oesophagus [1]. Pathophysiology of GERD makes the cardiac sphincter located at the upper part of the stomach lose its functionality, which would otherwise prevent the backflow of stomach content. Alginate and bicarbonate in the presence of acid forms raft that acts as a physical barrier and prevents the reflux in GERD. Alginate gets converted to alginic acid gel and bicarbonate liberates carbon dioxide in the presence of stomach acid. The evolved carbon dioxide gets entrapped into the gel-forming raft [710]. Additionally, alginate has the favorable adhesion property that makes it adhere to the oesophageal tissue and help the raft to act strongly against acid refluxes [11].

The challenges of the existing liquid dosage form can easily be overcome by alginate powder for suspension. The powder can be packed in a sachet as a single unit dosage form rather than a multidosage form and can be easily administered. Sachet has better patient compliance with respect to handling and carrying. Moreover, powder dosage form has better stability than oral liquid suspension form.

Anti-reflux suspension is generally used in combination with antacid, histamine type- 2 receptor antagonists; promotility agent and a proton pump inhibitor for improved therapeutic benefits [12, 13]. In order to overcome the poor solubility of alginate powder, microcrystalline cellulose and sodium carboxymethyl cellulose (CMC) a co-processed excipient (avicelCL611) was used as the suspending agent. The optimized formulation was tested for its physical attributes like raft strength, viscosity, $\mathrm{pH}$, formation speed, floatation, acid neutralizing capacity [14]. Ranitidine was incorporated in alginate powder to form a powder for suspension and tested for its functionality. Ranitidine is widely prescribed in the treatment of GERD, and the recommended adult oral dosages are 150 $\mathrm{mg}$ (b. i.d.) or $300 \mathrm{mg}$ (q. d.), preferably $150 \mathrm{mg}$ (q. i.d.). The conventional $150 \mathrm{mg}$ ranitidine can inhibit the acid secretion only up to 3-5 $\mathrm{h}$ and not for $10 \mathrm{~h}$. The increase in dosage $300 \mathrm{mg}$, however, leads to plasma fluctuation [15]. This necessitates the development of a controlled release system for the treatment of GERD [16].

In this context, the present work was focused on the development of ranitidine alginate powder for suspension which controls the refluxes, neutralize the acid and reduce acid secretion in the stomach in GERD. This novel suspension reacts with stomach acid and neutralize the excess acid, raft act as a physical barrier and floats over stomach acid for several hours and continuously releases ranitidine in stomach thereby bringing about the desired three therapeutic effect in a single formulation.

The results were assessed using Minitab statistical software. The formulation with alginate $750 \mathrm{mg}$ was shown good physical quality attributes and further studied for in vitro dissolution in SGF up to $10 \mathrm{~h}$.

\section{MATERIALS AND METHODS}

\section{Materials}

Ranitidine HClUSP/NF was generously donated by Umedica Laboratories Pvt. Ltd., Mumbai, India. Protanol L FR 5/60 USP/NF (sodium alginate), Avicel PH105 USP/NF (microcrystalline 
cellulose), avicelCL611USP/NF (colloidal microcrystalline cellulose) was kindly provided by FMC Biopolymer, USA. sodium bicarbonate USP/NF manufactured by Innophos,scoraliteLL250 USP/NF (calcium carbonate), pharmacoat645 USP/NF (hypromellose) manufactured by SHIN-ET-SU, celsphereCP102 (MCC sphere) manufactured by Ashikasei, Japan and magnesium hydroxide USP/NF (HD5) manufactured by ICL were supplied by Signet Chemical Corporation, India. Eudragit E100 USP/NF and aerosil200 USP/were manufactured and donated by Evonik industry, Germany. Sucralose manufactured and supplied by JK Sucralose, China. Aluminium hydroxide, mixed fruit flavour, was purchased from Central Drug House, Delhi, India was usedto USP/NF grade and Hydrochloric acid (SD fine chem Ltd.), Sod. di-hydrogen phosphate (SD fine chem Ltd.) and water were HPLC gradient grade.

\section{Preparation of ranitidine pellets}

MCC sphere 350 micron were coated with ranitidine, followed by $3 \%$ seal coating by hypromellose and $5 \%$ functional coat by ethylcellulose pre-plasticized by 25\% triethyl citrate (TEC) to retard the initial drug release in dosage form before administration. The coating was carried out by palm-glatt GPCG 1.1 using $1.0 \mathrm{~mm}$ atomizer spray at $38{ }^{\circ} \mathrm{C}$ product temperature with airflow of $70-80$ CFI and 8-12 g/min spray rate. The coating liquid was prepared as $15 \% \mathrm{w} / \mathrm{v}$ TDS (total dispersed solid) for a batch size of $300 \mathrm{~g}$.

\section{Preparation of ranitidine alginate powder for suspension}

Protanal LFR5/60, Avicel PH105, sodium bicarbonate, calcium carbonate were passed through 425-micron sieve and aluminum hydroxide, magnesium hydroxide, avicelCL611, sucralose, mixed fruit flavour, aerosil 200 were passed through 250 micron separately and blended in turbula blender at $20 \mathrm{rpm}$ for $10 \mathrm{~min}$ blended powders (R13) again pass through 425-micron sieve and blended with coated ranitidine $\mathrm{HCl}$ pellets equivalent to $300 \mathrm{mg}$ of ranitidine for another $5 \mathrm{~min}$. to achieve best homogeneity (table 1). Powder was reconstituted with $20 \mathrm{ml}$ of water and used for further analysis.

Table 1: Formulation details

\begin{tabular}{|c|c|c|c|c|c|c|c|c|c|c|}
\hline Ingredients & $\begin{array}{l}\text { Sod. } \\
\text { Alginate } \\
\text { (mg) }\end{array}$ & $\begin{array}{l}\text { Avicel } \\
611 \\
(\mathrm{mg})\end{array}$ & $\begin{array}{l}\text { MCC } \\
\text { PH105 } \\
\text { (mg) }\end{array}$ & $\mathrm{NaHCo}_{3}(\mathrm{mg})$ & $\mathrm{AlOH}_{3}$ (mg) & $\begin{array}{l}\mathrm{MgOH}_{2} \\
\text { (mg) }\end{array}$ & $\begin{array}{l}\mathrm{CaCO}_{3} \\
\text { (mg) }\end{array}$ & $\begin{array}{l}\text { MF } \\
\text { Flavor(mg) }\end{array}$ & $\begin{array}{l}\text { Sucralose } \\
\text { (mg) }\end{array}$ & $\mathrm{SiO}_{2}(\mathrm{mg})$ \\
\hline R1 & 250 & 125 & 375 & 267 & 110 & 97.5 & 375 & 10 & 50 & 10 \\
\hline $\mathrm{R} 2$ & 500 & 125 & 375 & 267 & 110 & 97.5 & 375 & 10 & 50 & 10 \\
\hline R3 & 750 & 125 & 375 & 267 & 110 & 97.5 & 375 & 10 & 50 & 10 \\
\hline $\mathrm{R} 4$ & 500 & 125 & 375 & 267 & 110 & 97.5 & 188 & 10 & 50 & 10 \\
\hline R5 & 500 & 125 & 375 & 267 & 110 & 97.5 & 563 & 10 & 50 & 10 \\
\hline R6 & 500 & 125 & 375 & 134 & 110 & 97.5 & 375 & 10 & 50 & 10 \\
\hline R7 & 500 & 125 & 375 & 201 & 110 & 97.5 & 375 & 10 & 50 & 10 \\
\hline R8 & 500 & 500 & 375 & 267 & 110 & 97.5 & 375 & 10 & 50 & 10 \\
\hline R9 & 500 & 800 & 375 & 267 & 110 & 97.5 & 375 & 10 & 50 & 10 \\
\hline $\mathrm{R} 10$ & 500 & 125 & 563 & 267 & 110 & 97.5 & 375 & 10 & 50 & 10 \\
\hline R11 & 500 & 125 & 750 & 267 & 110 & 97.5 & 375 & 10 & 50 & 10 \\
\hline R12 & 500 & 125 & 375 & 267 & 220 & 195 & 375 & 10 & 50 & 10 \\
\hline R13 & 750 & 125 & 375 & 201 & 110 & 97.5 & 375 & 10 & 50 & 10 \\
\hline R13p & 0 & 125 & 375 & 201 & 110 & 97.5 & 375 & 10 & 50 & 10 \\
\hline
\end{tabular}

p-formulation without Alginate

\section{Preparation of SGF (0.1NHCl-pH1.2)}

$100 \mathrm{ml}$ purified water was added in to $8.5 \mathrm{ml}$ of concentrated hydrochloric acid and further added $700 \mathrm{ml}$ of purified water. It was permitted to cool and made up to 1000 mlwith purified water.

\section{Viscosity}

The viscosity of the formulation was measured by using rheometer (model-Discovery HR-3, make-TA instruments). The rheometer is a precise instrument that contains the material of interest in a geometric configuration, controls the environment around it and applies and measures stress, strain and strain rate more accurately. The sample was applied on the lower fixed plate and geometry of $60 \mathrm{~mm}$ stainless steel parallel plate was used with a gap of 800 micron. After equilibrating at 25 ${ }^{\circ} \mathrm{C}$ for $1 \mathrm{~min}$., a continuous shear rate of 0.1 to $500 \mathrm{~s}-1$ was applied. The viscosity at lower shear rate was considered.

\section{Acid neutralizing capacity}

In vitro acid neutralizing capacity (ANC) helps to understand in vivo efficiency of the formulation to neutralize stomach acid. Formulation after reconstitution with $20 \mathrm{ml}$ of water was diluted to $70 \mathrm{ml}$ and mixed thoroughly for $1 \mathrm{~min}$. and stirred at a speed of $300 \pm 30 \mathrm{rpm}$. $30 \mathrm{ml}$ of $1.0 \mathrm{~N}$ hydrochloric acid was hereby added and stirred for another $15 \mathrm{~min}$. Excess hydrochloric acid was titrated with $0.5 \mathrm{~N}$ sodium hydroxide to attain a stable $\mathrm{pH}$ of 3.5. The number of mole equivalents of acid consumed (ACN) was calculated by the formula $(1)[17,18]$

$$
\text { Total mEq }=\left(30 \mathrm{X} \mathrm{N}_{\mathrm{HCL}}\right)-\left(\mathrm{V}_{\mathrm{NaOH}} \mathrm{X} \mathrm{N}_{\mathrm{NaOH}}\right)^{---------1}
$$

\section{pH of suspension}

$\mathrm{pH}$ was measured using a pH meter (Model-Five Easy Plus, makeMettler Toledo) after calibration with $\mathrm{pH} 7.00$ and $\mathrm{pH} 4.00$ buffer. The electrode surface was cleaned and placed in to20 ml reconstituted, suspension at room temperature $\left(27 \pm 2{ }^{\circ} \mathrm{C}\right)$ and $\mathrm{pH}$ was noted after stabilization of signals.

\section{Raft weight, volume, and thickness}

The maximum dose of the formulation was transferred to $250 \mathrm{ml}$ beaker containing $150 \mathrm{ml}$ of $0.1 \mathrm{NHCl}$ heated and maintained at $37^{\circ} \mathrm{C}$ temperature in a water bath for $30 \mathrm{~min}$. The beaker used for raft formation was pre-weighed (W1) and the upper and lower position of the raft was marked from the outer side of the beaker. The total weight of the beaker after raft formation was measured (W2). The excess acid was decanted, and the raft was transferred to a weighing boat and after $30 \mathrm{sec}$., the weight of raft (W3) was measured by removing excess supernatant liquid. The remaining liquid was removed from the beaker and filled with water up to the upper mark and weighed (W4). The volume of raft was calculated by formula (2).

$$
\text { Raft volume }=\left(\mathrm{W}_{4}-\mathrm{W}_{1}\right)-\left(\mathrm{W}_{2}-\mathrm{W}_{1}-\mathrm{W}_{3}\right)----------2
$$

The thickness of the raft from the upper and lower marked position was measured by using calibrated vernier caliper, and noted in millimetre $[7,8]$.

\section{Formation speed, coherence, and flotation of raft}

Raft formation was done as per the procedure mentioned previously and observed for speed, coherence and flotation. The formation speed was noted using calibrated stopwatch from the time of addition of the sample to $150 \mathrm{ml} 0.1 \mathrm{NHClto}$ the formation of a floating raft. Flotation was evaluated as complete if all the insoluble materials rose to the surface. If insoluble materials sank to the bottom and remain there for $30 \mathrm{~min}$., it was considered as partial flotation. The coherence of raft was assessed during removal of the raft from the beaker for weighing; Coherence is good if the raft was held substantially as a single mass, but poor if it gets broken into 
two or more pieces of [7].

\section{Raft strengths}

Raft was formed by adding a maximum recommended dose of formulation of sodium alginate in $250 \mathrm{ml}$ beaker with internal diameter $65 \mathrm{~mm}$ containing $150 \mathrm{ml}$ of $0.1 \mathrm{~N} \mathrm{HCl}$ preheated and maintained at $37{ }^{\circ} \mathrm{C}$ in a water bath; in which L-shaped probe was suspended such that the vertical arm of the probe hangs down the centre axis of the beaker and the horizontal arm was in the lower third of the acid. After $30 \mathrm{~min}$., the beaker was removed from the water bath and transferred to Texture analyser (Model-TX plus, make-stable microsystem, UK). The ' $\mathrm{L}$ ' shape probe was attached to the arm of texture analyser, and the probe was lifted through the raft at a speed of $5 \mathrm{~mm} / \mathrm{sec}$. The peak force during upward movement was recorded as raft strength in gram $[7,19]$. The diagram of the raft strength measurement set up is shown in fig. 1 .

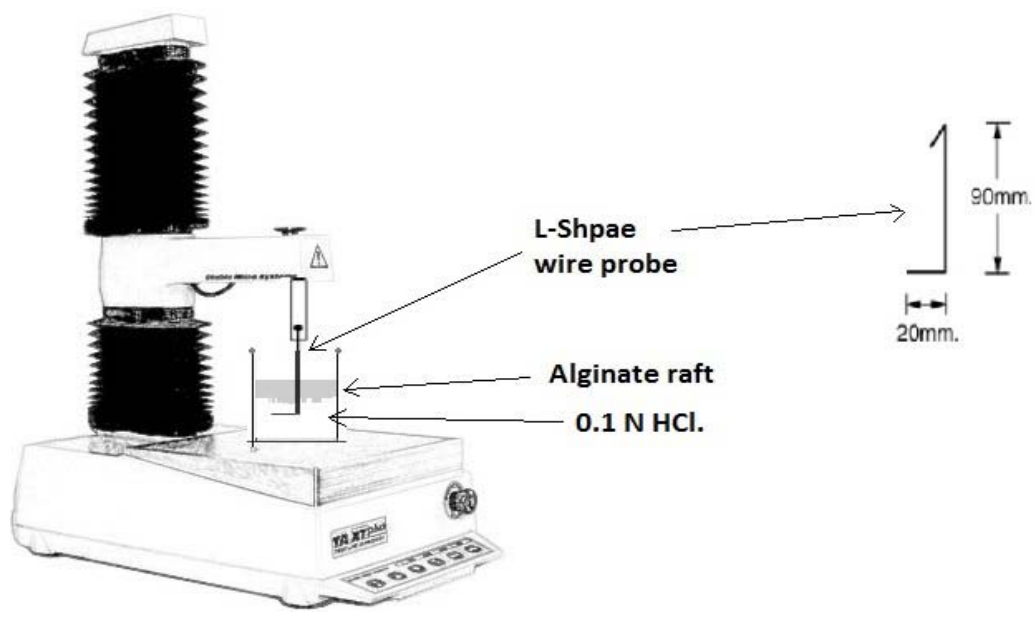

Fig. 1: Texture analyser: raft strength measurement. (TA. XT Plus, texture technologies, scarsdale, NY)

\section{Raft density}

A volume equivalent to $10 \mathrm{~g}$ of a sample of the formulation was added to $100 \mathrm{ml}$ measuring cylinder containing $50 \mathrm{ml}$ of $0.1 \mathrm{NHCl}$ $(\mathrm{pH}$ 1.2). Raft volume was noted after $10 \mathrm{~min}$, and density $(\mathrm{g} / \mathrm{ml})$ was calculated for each the formulation separately. Lower the density, the better the flotation; the density of formulation is expected to be less than the simulated gastric fluid [14].

\section{Resilience}

The anti-reflux formulation should have enough resilience to withstand in peristaltic waves of the stomach. The objective of this test was to understand the longevity of the raft under vigorous movement conditions. The sample formulation was placed in petri dish with ID $90 \mathrm{~mm}$, and $17 \mathrm{~mm}$ depth and kept at the bottom of dissolution bowl (dissolution apparatus type-2, model-AT 7 Smart semi; make-SOTAX AG, Switzerland). $0.1 \mathrm{NHCl}$ preheated at $37^{\circ} \mathrm{Cwas}$ transferred slowly into a bowl and allow raft formation for $30 \mathrm{~min}$. The paddle rotation was kept at the 100rpmmimicking peristaltic movement. The rafts were assessed visually for gel size and coherence after regular intervals of agitation of $2,5,10,20,30,45$, and to a maximum of $60 \mathrm{~min}$. or until the time at which the raft could no longer be detected.

\section{In vitro dissolution test}

The release of ranitidine from the raft forming suspension was studied using USP type-2 (paddle) apparatus (model-AT 7 Smart semi; make-sotax AG, Switzerland) at $37{ }^{\circ} \mathrm{C}$ and paddle rotating speed of 50rpm. This speed is slow enough to avoid any breakage of the raft and maintained with mild agitation condition believed to exist in vivo. Final formulation after reconstitution with $20 \mathrm{ml}$ water was added to the dissolution bowl containing $0.1 \mathrm{~N}$ hydrochloric acid (pH 1.2). Sample (5 ml) was taken out and replenished with fresh medium after $30,45,60,120,240,360,420$ and $600 \mathrm{~min}$. The amount of ranitidine in the withdrawn sample was measured by HPLC using Eclipse XDB C18 $(150 \mathrm{~mm} \times 4.6 \mathrm{~mm}, 5 \mu \mathrm{m})$ column. Mobile phase A-2\% tri-ethanolamine at $\mathrm{pH} 3$ adjusted with orthophosphoric acid and mobile phase B- $100 \%$ methanol was used. The eluent was monitored with UV detector set at $313 \mathrm{~nm}$ at 1 $\mathrm{ml} / \mathrm{min}$ flow rate with injection volume $25 \mu \mathrm{l}[20,21]$. Dissolution was carried out in three units (triplicate) and the standard deviation was calculated. A curve of percent ranitidine release against time was plotted to illustrate the drug release profile.

\section{Stability study}

This study was planned with an objective to understand the impact of time on quality attributes of the formulation. The optimized formulation (R13) was exposed to ambient condition (temperature$25 \pm 2{ }^{\circ} \mathrm{C}, \mathrm{RH}-60 \pm 5 \%$ ) and accelerated condition (temperature- $40 \pm 2$ ${ }^{\circ} \mathrm{C}, \mathrm{RH}-75 \pm 5 \%$ ) up to three months in aluminum sachet. All the samples were tested for assay, dissolution and compared with the initial result after $3 \mathrm{mo}$. The chromatogram of samples was compared and studied for the peak and its area under the integrated curve.

\section{RESULTS AND DISCUSSION}

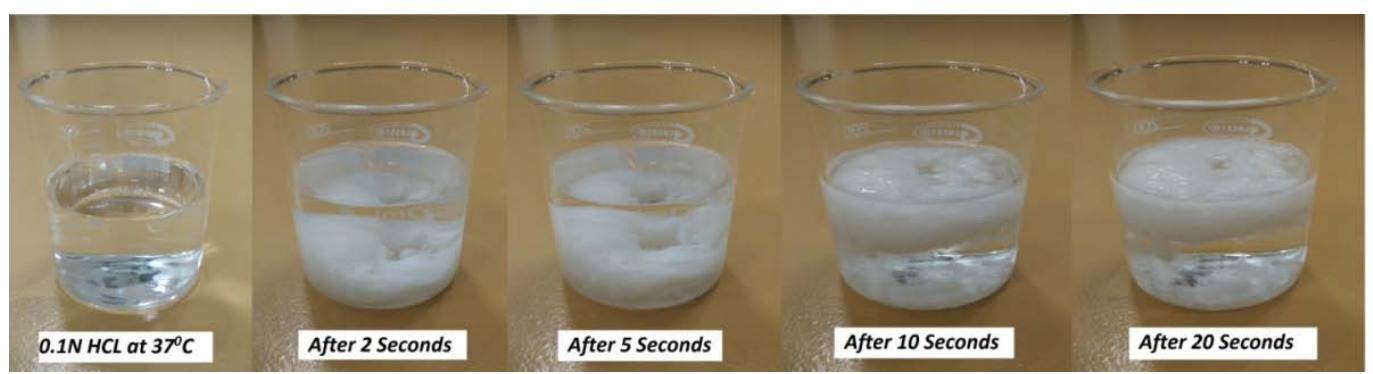

Fig. 2: Development of raft in $0.1 \mathrm{~N} \mathrm{HCl}$ at $37^{\circ} \mathrm{C}$; R13 less than $9 \mathrm{sec}$ and other formulations between $9-20$ sec 


\section{Viscosity}

The viscosity of formulationR1, R2, and R3shows that the alginate acts as a viscosifying agent and helps to form a stable suspension.

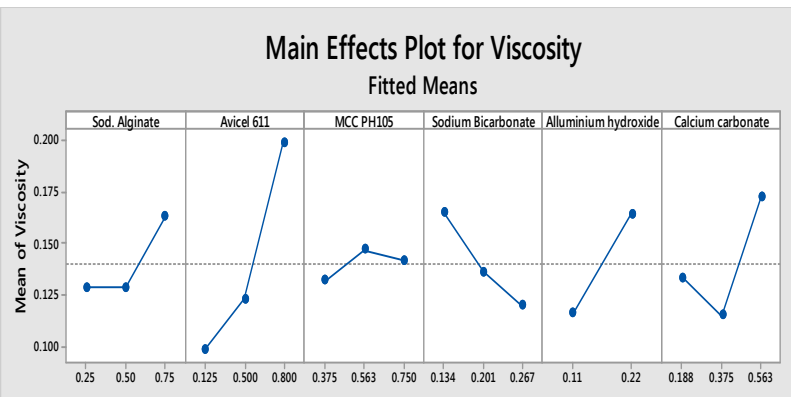

Formulation R2, R8, R9 have a different concentration of viscosifying agent, build up high viscosity y, but do not imply any positive effect on raft strength. All the formulation R1 to R13 have optimum viscosity without any significant variation (fig. 3).

Fig. 3: Main effect plot for viscosity and a comparative bar chart of viscosity for all formulation

\section{Acid neutralizing capacity (ANC)}

ANC is very important to understand in vivo effect of the formulation to neutralize excess stomach acid. The existing marketed formulation has similar acid neutralization capacity which fall in the range of 15 to $35 \mathrm{mEq}$ [7]. The formulation expected to have better acid neutralization to treat GERD symptoms effectively. Alginates neutralize stomach acid up to a certain extent; higher concentration helps to achieve better neutralization. The higher concentration of alkalizing agent sodium bicarbonate (R6, R7), aluminum hydroxide, magnesium hydroxide (R12, R13) and calcium carbonate (R4, R5) have a positive effect on the acid neutralization, however higher concentration shows a negative effect on raft strengths. Hence it is very important to use an alkalizing agent at an optimum level (fig. 4).
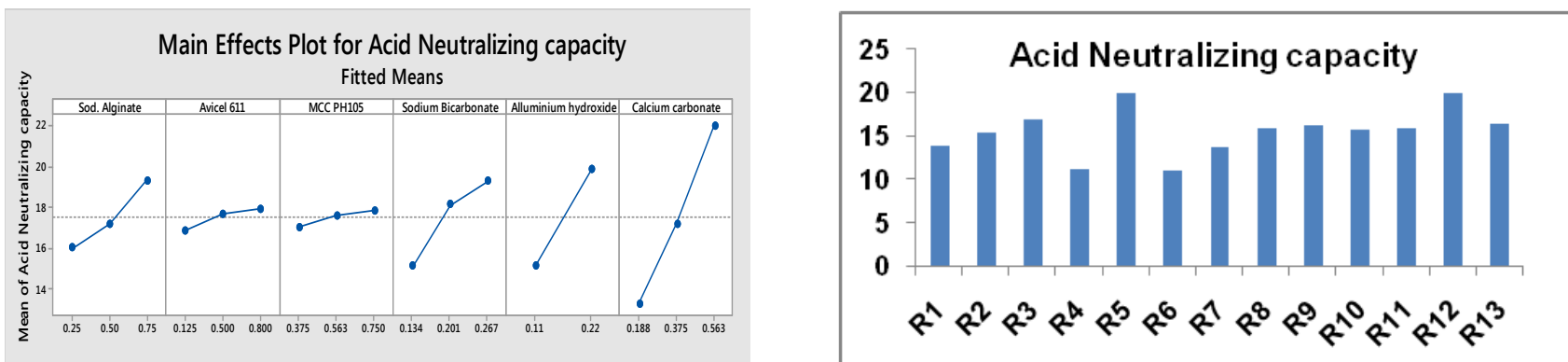

Fig. 4: Main effect plot of acid neutralization capacity (ANC) and it's a comparative bar chart

\section{pH}

All the formulations has $\mathrm{pH}$ between 9.3 to 9.5 without any significant variation. The slightly higher $\mathrm{pH}$ is justifiable for the formulation intended for antacid and anti-reflux action.

\section{Raft weight and volume}

Weight and volume are a physical phenomenon, understood after raft formation in $0.1 \mathrm{NHCl}$. The mechanism of action of the anti-reflux formulation is to act as a physical barrier at oesophageal sphincter to prevent acid reflux in the oesophagus. So, it is very necessary to evaluate and understand the physical strength of raft. The volume and weight are the physical parameters and are observed higher variation in results. The main effect plot of all the formulations for weight and volume implies that alginate has an impact on the weight and volume of raft and responsible to obtain higher weight and volume (fig. 5).
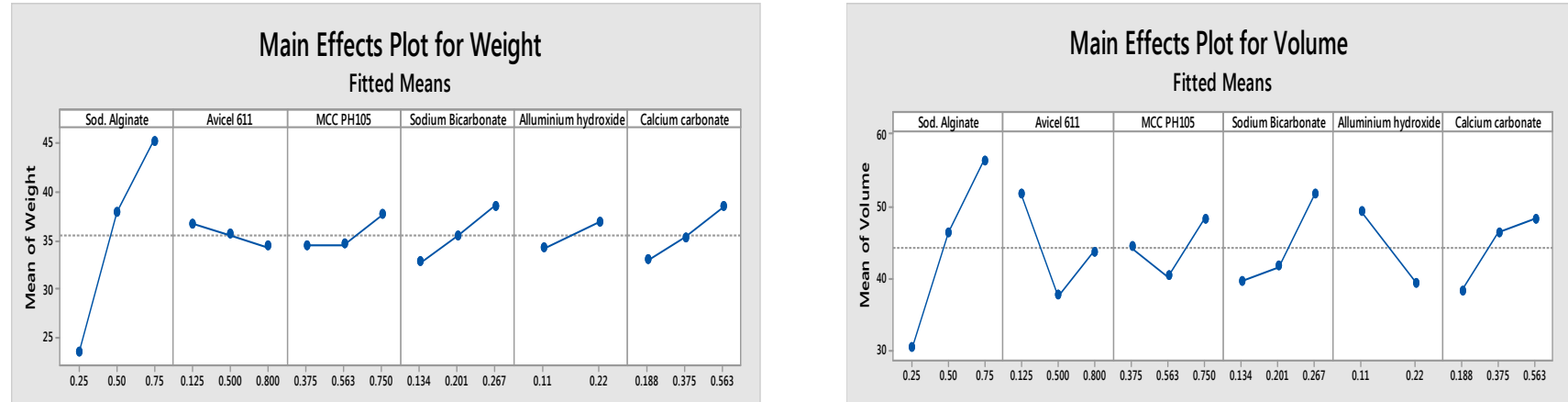

Fig. 5: Main effect plot for volume and weight of raft 


\section{Formation speed, coherence and flotation of raft}

Raft formation speed was observed while formation; and coherence and flotation was observed after raft formation which has significance in the onset of anti-reflux action. All the formulations have shown the onset of anti-reflux action less than 20 seconds, with proper coherence and flotation; except formulation R6 with $133 \mathrm{mg}$ of $\mathrm{NaHCO}_{3}$ and formulation R3 with $750 \mathrm{mg}$ of alginate has not shown uniform coherence.

\section{Raft strengths and density}

Raft strength is a very important quality attribute to understand the mechanism of anti-reflux action. The alginate formulation in contact with stomach acid forms a raft, which acts as a surrogate for oesophagus sphincter. The main effect plot (Fig.6) of raft strength reveals that the formulation (R3, R13) have higher raft strengths and lower density in comparison with other formulations. However, formulation R3 has not shown effective coherence and may fail to act against reflux in stomach. Whereas, formulation R13 has raft strengths of $17 \pm 1 \mathrm{~g}$, which is better than any available marketed products [7]. The concentration of alginate is critical in the formulation for raft strength. Raft strength and density are inversely proportional to each other.
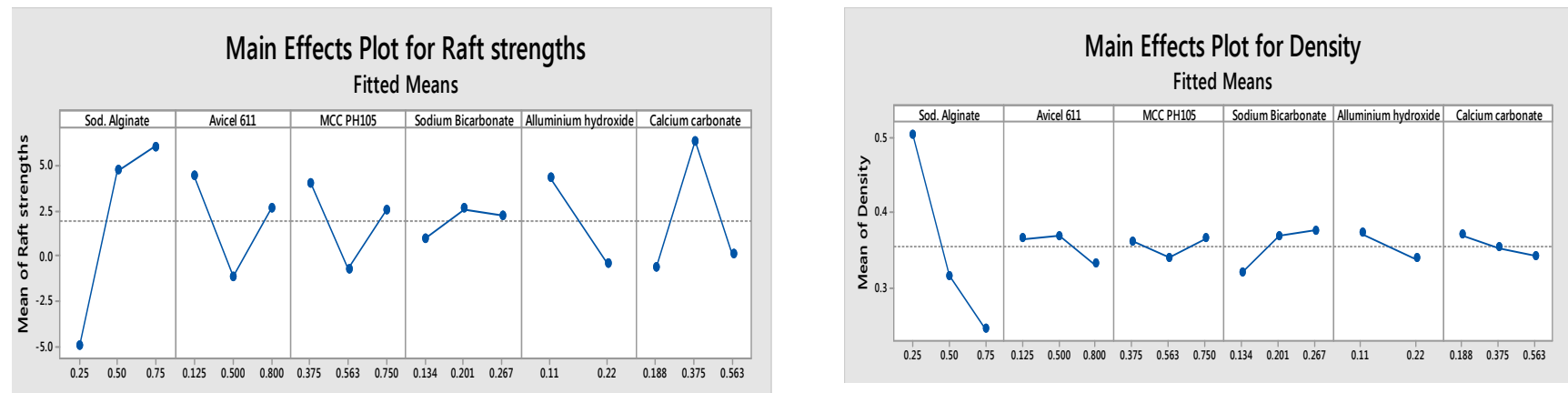

Fig. 6: Main effect plot for strengths and density of raft

Possible interaction has been observed in the interaction plot between alginate and alkalizing agent (sodium bicarbonate, calcium carbonate) with respect to raft strength. An alkalizing agent like bicarbonate and hydroxide at higher concentration has shown negative interaction with sodium alginate, which results to loss of raft strength but have been used even in the commercially available anti-reflux product in the market to maintain its ANC [7].

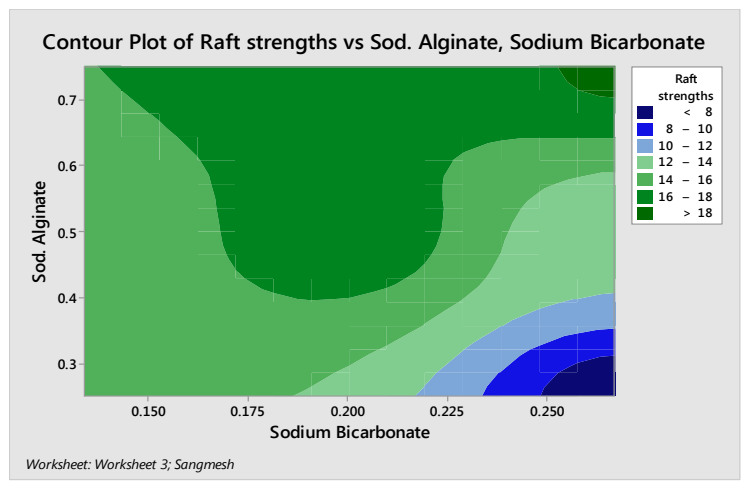

The counterplot helps us to understand the design space of the alkalizing agent in the formulation. The counterplot shows that sodium bicarbonate at a lower concentration (200 $\mathrm{mg}$ to $250 \mathrm{mg}$ ) and alginate at higher concentration ( $\geq 750 \mathrm{mg}$ ) gives stronger raft strength( $>16 \mathrm{~g}$ ). Calcium carbonate within a specific range (350 $\mathrm{mg}$ to $400 \mathrm{mg}$ ) gives better raft strength, whereas, hydroxides of aluminum and magnesium are not contributing positively to the raft strength and hence recommended to use at a lower level (fig. 7 and fig. 8).

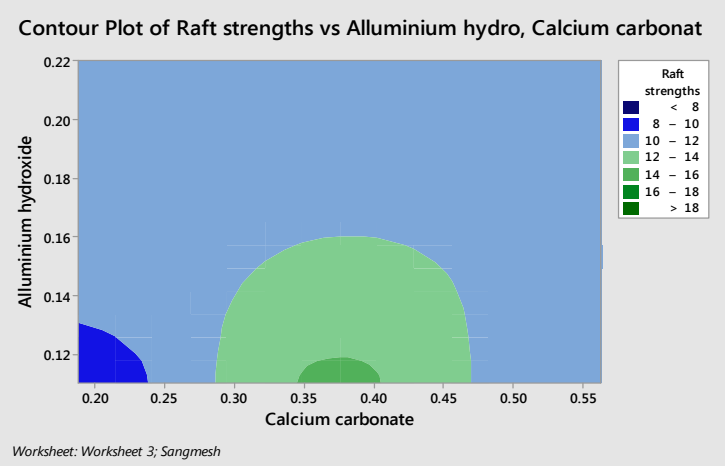

Fig. 7: Counter plot of $\mathrm{NaHCO}_{3}$, alginate, $\mathrm{Al}(\mathrm{OH})_{3}, \mathrm{Mg}(\mathrm{OH})_{2}$ with raft strengths

\section{Raft resilience}

Raft resilience of formulation (R1) with $250 \mathrm{mg}$ of sodium alginate and formulation (R4) with $188 \mathrm{mg}$ calcium carbonate has shown lower resilience than other formulations. The formulation (R13) with $750 \mathrm{mg}$ of sodium alginate and $375 \mathrm{mg} \mathrm{CaCO}{ }_{3}$ has shown good resilience. Moreover, formulation (R13) which was tested for in vitro dissolution shown resilience up to $10 \mathrm{~h}$. Resilience and raft strength is directly proportional to each other, which is much better than the commercially available anti-reflux products [7].

\section{In vitro dissolution test}

The in vitro results show that formulation R3 and R13 have good quality attributes with respect to raft strength and ANC. Formulation R3 fails to have good coherence as compared to formulation R13. Considering all the quality attributes, formulation R13 has achieved excellent raft quality attributes and was studied further for in vitro drug release. The cumulative percentage release of ranitidine from ranitidine suspension (R13) with alginate and without alginate is summarized in table 2 . The ranitidine suspension without alginate (R13p) does not form raft and shows immediate release without any control over the release rate. The formulation with alginate (R13) shows zero-order controlled release in $0.1 \mathrm{~N} \mathrm{HCl}$ up to $10 \mathrm{~h}$ (table 2, fig. 9).

\section{Stability study}

The optimized formulation (R13) was sealed in aluminium sachet and exposed to accelerated and ambient conditions and analysed for drug release. The release profile of ranitidine after three months as compared to that of initial has shown (fig. 10, table 3) no significant change and thus follows the same release pattern. The chromatogram of both was compared to understand any change in the potency (table 4).

Further, there are no significant changes observed in drug release even after three months of exposure to accelerated stability conditions $\left(40 \pm 2{ }^{\circ} \mathrm{C}, \mathrm{RH}-75 \pm 5 \%\right)$ suggesting that the product will 


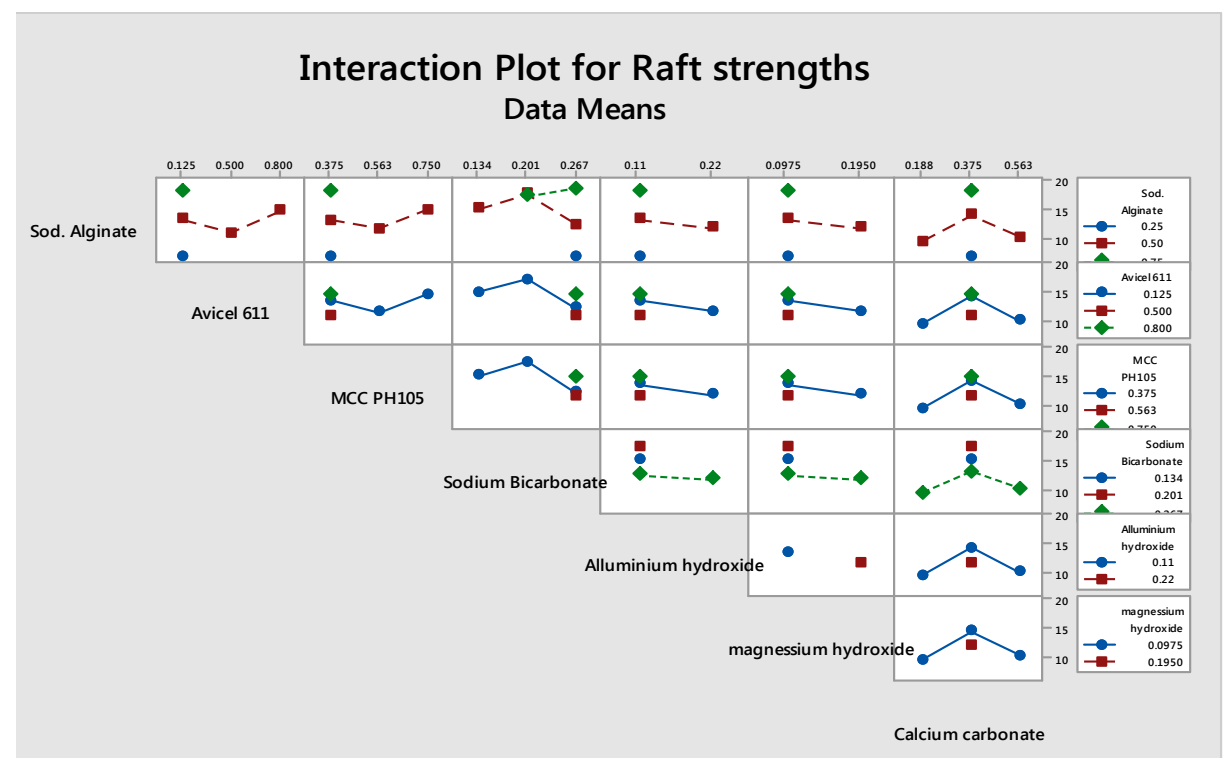

Fig. 8: Interaction plot for raft strengths

Table 2: Formulation in vitro evaluation details

\begin{tabular}{|c|c|c|c|c|c|c|c|c|c|c|c|c|}
\hline $\begin{array}{l}\text { Ingredient } \\
\mathrm{s}\end{array}$ & $\begin{array}{l}\text { Formatio } \\
\text { n speed } \\
\text { (s) }\end{array}$ & $\begin{array}{l}\text { Cohere } \\
\text { nce }\end{array}$ & $\begin{array}{l}\text { Flotat } \\
\text { ion }\end{array}$ & $\begin{array}{l}\text { Thickness } \\
(\mathrm{mm})\end{array}$ & $\begin{array}{l}\text { Weight } \\
\text { (g) }\end{array}$ & $\begin{array}{l}\text { Volu } \\
\text { me } \\
(\mathrm{ml})\end{array}$ & $\begin{array}{l}\text { ANC } \\
(\mathrm{mEq})\end{array}$ & $\begin{array}{l}\text { Raft } \\
\text { strengt } \\
\text { hs (g) }\end{array}$ & $\begin{array}{l}\text { Resili } \\
\text { ence } \\
\text { (min) }\end{array}$ & $\begin{array}{l}\text { Density } \\
(\mathrm{g} / \mathrm{ml})\end{array}$ & $\begin{array}{l}\text { Viscosity (Pa. } \\
\text { s) }\end{array}$ & pH \\
\hline R1 & $14 \pm 2$ & $1^{*}$ & $1^{*}$ & $16 \pm 4$ & $25 \pm 5$ & $52 \pm 2$ & $14 \pm 1$ & $7 \pm 3$ & 40 & $0.56 \pm 0.1$ & $0.0089 \pm 0.2$ & $9.3 \pm 0.1$ \\
\hline $\mathrm{R} 2$ & $10 \pm 3$ & $1^{*}$ & $1^{*}$ & $19 \pm 3$ & $38 \pm 4$ & $62 \pm 3$ & $16 \pm 2$ & $16 \pm 4$ & $>60$ & $0.37 \pm 0.3$ & $0.0192 \pm 0.3$ & $9.3 \pm 0.3$ \\
\hline R3 & $20 \pm 1$ & $0^{*}$ & $1^{*}$ & $21 \pm 5$ & $48 \pm 6$ & $84 \pm 3$ & $17 \pm 1$ & $19 \pm 2$ & $>60$ & $0.29 \pm 0.4$ & $0.0328 \pm 0.3$ & $9.3 \pm 0.2$ \\
\hline $\mathrm{R} 4$ & $7 \pm 4$ & $1^{*}$ & $1^{*}$ & $20 \pm 3$ & $37 \pm 4$ & $60 \pm 2$ & $11 \pm 2$ & $9 \pm 3$ & 55 & $0.38 \pm 0.3$ & $0.0273 \pm 0.4$ & $9.3 \pm 0.1$ \\
\hline $\mathrm{R} 5$ & $18 \pm 2$ & $1^{*}$ & $1^{*}$ & $17 \pm 4$ & $43 \pm 4$ & $70 \pm 3$ & $20 \pm 2$ & $10 \pm 3$ & $>60$ & $0.36 \pm 0.5$ & $0.0662 \pm 0.3$ & $9.5 \pm 0.3$ \\
\hline R6 & $18 \pm 3$ & $0^{*}$ & $1^{*}$ & $15 \pm 2$ & $34 \pm 5$ & $56 \pm 3$ & $11 \pm 1$ & $15 \pm 4$ & $>60$ & $0.31 \pm 0.3$ & $0.0542 \pm 0.2$ & $9.3 \pm 0.2$ \\
\hline R7 & $10 \pm 2$ & $1^{*}$ & $1^{*}$ & $17 \pm 4$ & $37 \pm 6$ & $64 \pm 2$ & $14 \pm 2$ & $17 \pm 3$ & $>60$ & $0.36 \pm 0.2$ & $0.0153 \pm 0.2$ & $9.3 \pm 0.3$ \\
\hline R8 & $10 \pm 1$ & $1^{*}$ & $1^{*}$ & $17 \pm 5$ & $38 \pm 5$ & $54 \pm 2$ & $16 \pm 1$ & $11 \pm 4$ & $>60$ & $0.37 \pm 0.3$ & $0.0331 \pm 0.3$ & $9.3 \pm 0.3$ \\
\hline R9 & $13 \pm 3$ & $1^{*}$ & $1^{*}$ & $16 \pm 3$ & $37 \pm 5$ & $60 \pm 1$ & $16 \pm 1$ & $15 \pm 2$ & $>60$ & $0.33 \pm 0.4$ & $0.1097 \pm 0.2$ & $9.3 \pm 0.2$ \\
\hline R10 & $10 \pm 3$ & $1^{*}$ & $1^{*}$ & $22 \pm 3$ & $40 \pm 4$ & $64 \pm 3$ & $16 \pm 2$ & $12 \pm 4$ & $>60$ & $0.34 \pm 0.2$ & $0.0236 \pm 0.3$ & $9.3 \pm 0.2$ \\
\hline R11 & $9 \pm 4$ & $1^{*}$ & $1^{*}$ & $22 \pm 5$ & $43 \pm 3$ & $72 \pm 2$ & $16 \pm 1$ & $15 \pm 3$ & $>60$ & $0.37 \pm 0.3$ & $0.0185 \pm 0.2$ & $9.3 \pm 0.3$ \\
\hline $\mathrm{R} 12$ & $10 \pm 2$ & $1^{*}$ & $1^{*}$ & $19 \pm 4$ & $42 \pm 5$ & $58 \pm 1$ & $20 \pm 1$ & $12 \pm 2$ & $>60$ & $0.33 \pm 0.3$ & $0.0574 \pm 0.3$ & $9.3 \pm 0.2$ \\
\hline $\mathrm{R} 13$ & $9 \pm 2$ & $1^{*}$ & $1^{*}$ & $19 \pm 2$ & $43 \pm 4$ & $62 \pm 3$ & $17 \pm 1$ & $18 \pm 2$ & $>60$ & $0.29 \pm 0.4$ & $0.0703 \pm 0.2$ & $9.3 \pm 0.2$ \\
\hline $\mathrm{R} 13 \mathrm{p}$ & \multicolumn{12}{|c|}{ No raft formation } \\
\hline
\end{tabular}

MF-mixed fruit, ANC-acid neutralization capacity. Note-1*-good/complete, $0^{*}$-Not good/partial, (value representthe mean \pm SD, $\mathrm{n}=3$ )

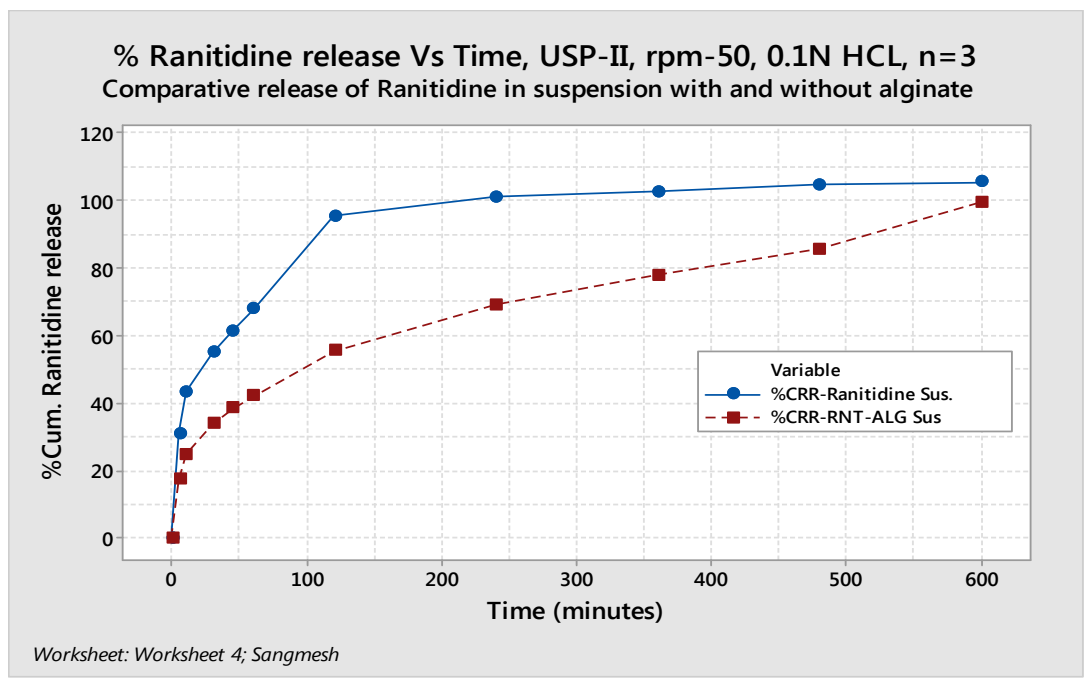

Fig. 9: In vitro release of ranitidine with alginate (R13), and without alginate suspensions (R13p); mean $\pm S D, n=3$ 


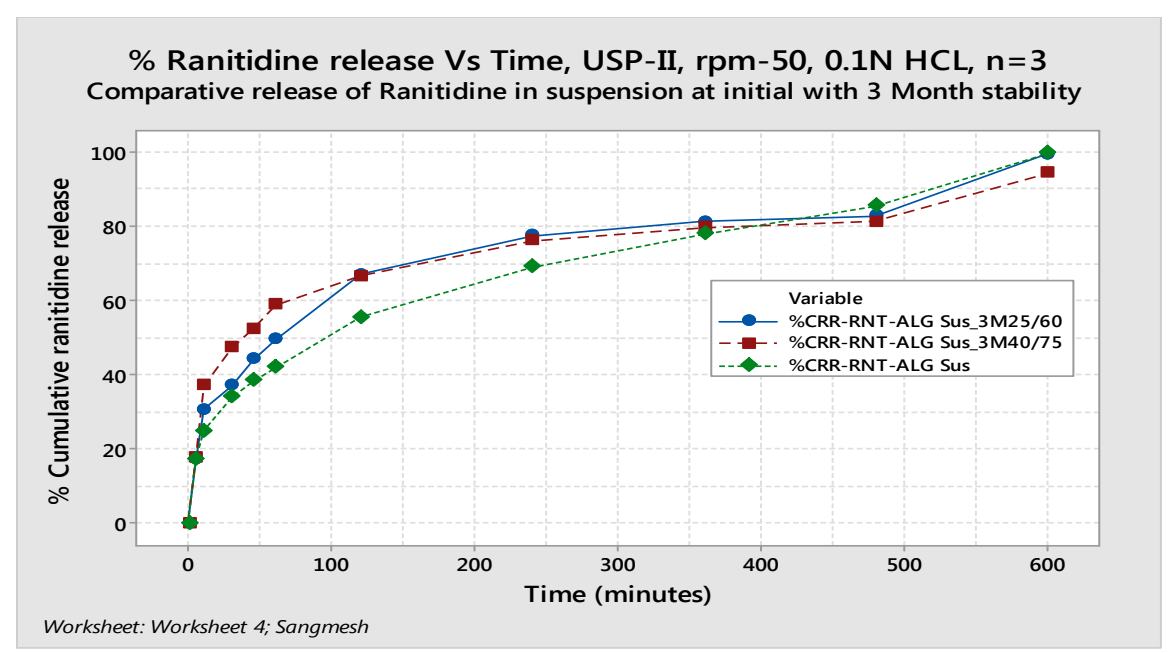

Fig. 10: In vitro release of R13 suspension initially and after 3 months at $25 / 60$ and 40/75; mean $\pm S D, n=3$

Table 3: Percent cumulative release of ranitidine alginate suspension (R13) in vitro dissolution study

\begin{tabular}{lllll}
\hline \multirow{2}{*}{ Time (min) } & Ranitidine suspension_R13p & Initial_R13 & 3 Mo 25-60_R13 & 3 Mo 40-75_R13 \\
\cline { 2 - 5 } & PCR \pm SD & PCR \pm SD & PCR \pm SD & PCR \pm SD \\
\hline 5 & $29.3 \pm 14.3$ & $16.3 \pm 0.3$ & $17.0 \pm 1.3$ & $17.6 \pm 1.1$ \\
10 & $41.0 \pm 19.3$ & $23.5 \pm 1.5$ & $30.6 \pm 3.8$ & $36.9 \pm 2.5$ \\
30 & $51.9 \pm 21.9$ & $32.0 \pm 3.0$ & $37.1 \pm 4.5$ & $47.4 \pm 2.9$ \\
45 & $57.9 \pm 23.7$ & $36.2 \pm 0.8$ & $44.1 \pm 4.3$ & $52.4 \pm 2.4$ \\
60 & $64.0 \pm 22.1$ & $43.9 \pm 3.3$ & $49.4 \pm 5.3$ & $58.7 \pm 2.3$ \\
120 & $90.2 \pm 0.6$ & $50.2 \pm 2.9$ & $66.9 \pm 10.8$ & $66.5 \pm 2.9$ \\
240 & $95.5 \pm 0.5$ & $66.5 \pm 4.8$ & $77.4 \pm 7.9$ & $76.1 \pm 4.3$ \\
360 & $97.0 \pm 0.6$ & $72.3 \pm 0.7$ & $81.4 \pm 6.2$ & $81.3 \pm 4.2$ \\
480 & $99.0 \pm 1.3$ & $85.6 \pm 0.7$ & $82.8 \pm 5.6$ & $94.3 \pm 1.9$ \\
600 & $99.6 \pm 1.0$ & $95.3 \pm 1.0$ & $99.6 \pm 1.4$ & \\
\hline
\end{tabular}

(PCR-Percent cumulative release represents; SD-standard deviation, value represent mean $\pm \mathrm{SD}, \mathrm{n}=3$ )

Table 4: Chromatogram of ranitidine $\mathrm{HCl}$ at initial and after three months of stability

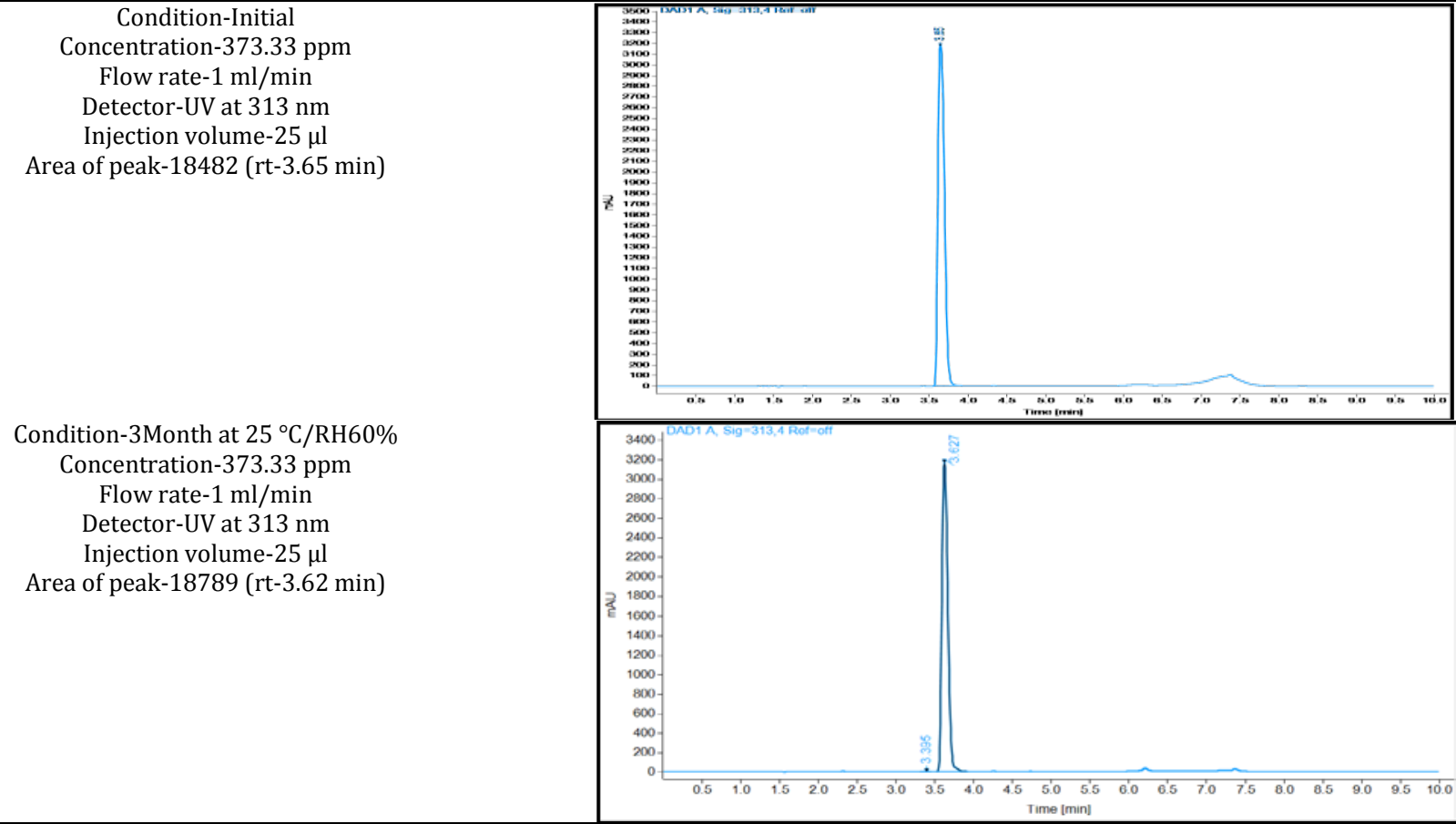


Condition-3Month $40{ }^{\circ} \mathrm{C} / \mathrm{RH} 75 \%$

Concentration-373.33 ppm

Flow rate- $1 \mathrm{ml} / \mathrm{min}$

Detector-UV at $313 \mathrm{~nm}$

Injection volume- $25 \mu \mathrm{l}$

Area of peak-18082 (rt-3.57 min)

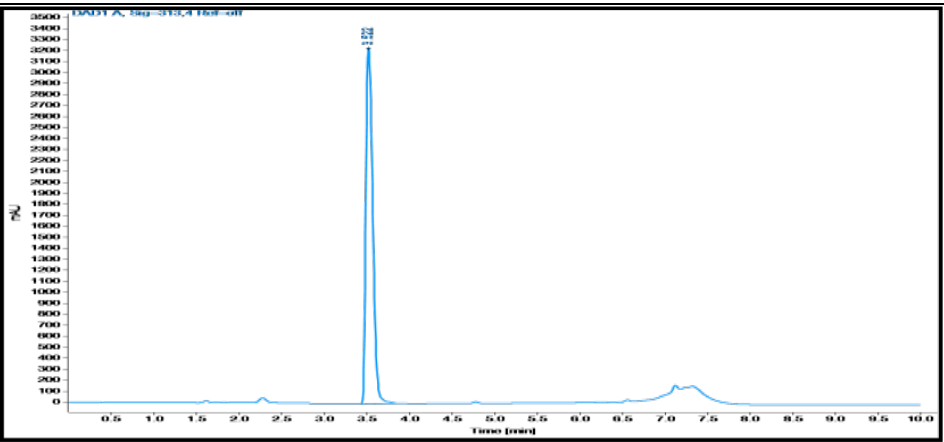

\section{CONCLUSION}

The developed powder for suspension has shown triple action combining antacid, anti-reflux and controlled release of active drug which normally necessitates the intake of three different drugs. The in vitro evaluation shows that formulation R13 containing $300 \mathrm{mg}$ of ranitidine and $750 \mathrm{mg}$ of alginate has sufficient strength with higher alkalizing agent than other formulations. This formulation even has better acid neutralization effect without compromising on the strength of the raft likely to occur with increasing concentration of alkalizing agent. The viscosity is satisfactory to hold the dispersed insoluble materials in the media uniformly. However, sedimentation would occur on prolonged standing of suspension and hence recommended to use immediately after reconstitution. In addition, flotation, $\mathrm{pH}$ coherence, weight and volume of raft facilitate better raft strength. The release profile in $0.1 \mathrm{~N} \mathrm{HCl}$ favours the release of ranitidine in stomach acid at a controlled rate up to $10 \mathrm{~h}$. The stability study implies that the formulation is stable up to three months of accelerated and ambient conditions of temperature and humidity. Thus, this novel formulation has greater potential to be developed as a multifunctional drug for the treatment of GERD.

\section{ACKNOWLEDGMENT}

The authors express their deep thanks to the Department of Chemistry, School of Advanced Sciences, Vellore Institute of Technology, Vellore for providing the necessary environment and knowledge source. Author is sincerely grateful to Dupont Nutrition and Health, India for providing required sodium alginate and research facility to carry out experimentation.

This research did not receive any specific grant from funding agencies in the public, commercial, or not-for-profit sectors.

\section{AUTHORS CONTRIBUTIONS}

All the authors have contributed equally

\section{CONFLICTS OF INTERESTS}

There is no conflict of interest from all the authors

\section{REFERENCES}

1. Dutta U, Armstrong D. Novel pharmaceutical approaches to reflux disease. Gastroenterol Clin N Am 2013;42:93-117.

2. Bennett R, Stanciu C. Alginate/Antacid in the reduction of gastro-oesophageal reflux disease. The Lancet 1974;109. Doi:https://doi.org/10.1016/S0140-6736(74)92340-X

3. Washington N, Washington C, Wilson G, Davis S. What is "Liquid Gaviscon"? A comparison of four international formulations. Int J Pharm 1986;34:105-9.

4. Mandlekar V, Marathe S, Devarajan V. A novel raft-forming antacid suspension using a natural dietary fibre. Int J Pharm 1997;148:117-21.

5. Strugala V, Dettmar W, Thomas C. Evaluation of an innovative over-the-counter treatment for symptoms of reflux disease: Quick-dissolving alginate granules. ISRN Pharm; 2012. p. 7.
6. MHRA. Medicines and Healthcare product Regulatory Agency, UK. Public assessment report, Gaviscon 250 Chewable Tablets; 2017. Available from: http://www.mhra.gov.uk/publicassessment-reports/. [Last accessed on 18 Jul 2018]

7. Hampson FC, Farndale A, Strugala V, Sykes J, Jolliffe IG, Dettmar PW. Alginate rafts and their characterisation. Int J Pharm 2005;294:137-47.

8. Sreejan M, Kanchi J, Kancherla RA, Laxmi KK. Alginate based raft forming tablets of enhanced bioavailability of tinidazole. Int J Appl Pahrma 2017;9:3, 55-60.

9. Johnson FA, Craig DQM, Mercer A, Chauhan S. The use of image analysis as a means of monitoring bubble formation in alginate rafts. Int J Pharm 1998;170:179-85.

10. Harshil PS, Shailesh TP, Patel CN. Gastro retentive drug delivery system: from concept to commercial success. J Crit Rev 2017;4:2,10-21

11. Richardson JC, Dettmar PW, Hampson FC, Melia CD. Oesophageal bioadhesion of sodium alginate suspensions: particle swelling and mucosal retention. Eur J Pharm Sci 2004;23:49-56.

12. Fass R, Bautista J, Janarthanan S. Treatment of gastroesophageal reflux disease. Clin Cornerstone 2003;5:18-29.

13. Mandel KG, Daggy BP, Brodie DA, Jacoby HI. Review article: alginate-raft formulations in the treatment of heartburn and acid reflux. Aliment Pharmacol Ther 2000;14:669-90.

14. Kerdsakundee N, Mahattanadul S, Wiwattanapatapee R. Development and evaluation of gastroretentive raft forming systems incorporating curcumin-Eudragit? EPO solid dispersions for gastric ulcer treatment. Eur J Pharm Biopharm 2015;94:513-20.

15. Trivedi ND, Trivedi UN, Patel MM, Patel JK, Bhandari A. Preparation and evaluation of floating matrix tablet of ranitidine. Am J Drug Discovery Dev 2011;1:8-23.

16. Washington N, Washington C, Wilson CG. Gastric distribution and residence time of two anti-reflux formulations. Int J Pharm 1987;39:163-71.

17. United State Pharmacopoeia (USP) 34 (National Formulary 29), Chapter $<301>$, Rockville MD: Pharmacopoeial Convention; 2017. Available from: http://www.pharmacopeia.cn/ v29240/usp29nf24s0_c301.html.asp. [Last accessed on 18 Jul 2018].

18. Washington N, Wilson CG, Davis SS. Evaluation of "raftforming" antacid neutralizing capacity: in vitro and in vivo correlations. Int J Pharm 1985;27:279-86.

19. The British Pharmacopoeia commission, British Pharmacopoeia, HMSO Publication: London; 2007. p. 664.

20. Sahoo BK, Mukherjee J, Pal TK. Development and validation of a high performance liquid chromatographic method for bio analytical application with ranitidine HCL. Int J Pharm Pharm Sci 2011;3:2-6.

21. Diane AAI, Patel R, Basit AW. Simple and universal HPLC-UV method to determine cimetidine, ranitidine, famotidine and nizatidine in urine: application to the analysis of ranitidine and its metabolites in human volunteers. J Chromatogr B 2007;860:235-40. 